\title{
Outdoor Operational Stability of Indium-Free Flexible Polymer Solar Modules Over 1 Year Studied in India, Holland, and Denmark**
}

\author{
By Dechan Angmo, Paul M. Sommeling, Ritu Gupta, Markus Hösel, Suren A. Gevorgyan, \\ Jan M. Kroon, Giridhar U. Kulkarni and Frederik C. Krebs*
}

We present an outdoor interlaboratory stability study of fully printed and coated indium-tin-oxide (ITO)-free polymer solar cell modules in JNCASR Bangalore (India), ECN (Holland), and DTU (Denmark) carried over more than 1 year. The modules comprising a fully printed and coated stack (Ag grid/PEDOT:PSS/ZnO/P3HT:PCBM/PEDOT:PSS/Ag grid) were prepared in two successive generations and evaluated for outdoor operational stability according to the test protocols laid out by the International Summit on OPV stability (ISOS-3). The modules $\left(70-100 \mathrm{~cm}^{2}\right.$ active area) were encapsulated between two sheets of low-cost plastic barrier material with the use of a UV curing adhesive. The impact of differences in the climatic conditions on the performance of the modules is highlighted and the performance of the modules under storage conditions in parallel with the outdoor study is investigated. While all Gen-I modules failed, the best devices of Gen-II module in which simple improvement in the encapsulation scheme (Gen-II modules) was carried out maintained 95\% of the initial performance after 1 year of outdoor testing. We provide detailed insight into the failure mode and offer a discussion on the need for improvement in flexible encapsulation. Finally, recommendations on future encapsulation schemes are also presented.

\section{Introduction}

Performance-to-cost ratio is the primary determinant for the commercial success of any technology. For solar cells, performance is determined by stability and power conversion efficiency, while cost is determined by all-inclusive materials,

[*] Prof. F. C. Krebs, D. Angmo, M. Hösel, Dr. S. A. Gevorgyan Department of Energy Conversion and Storage, Technical University of Denmark, Frederiksborgvej 399, DK-4000, Roskilde, Denmark

E-mail:frkr@dtu.dk

P. M. Sommeling, Dr. J. M. Kroon

ECN Solar Energy, P.O. Box 1, 1755 ZG Petten

R. Gupta, Prof. G. U. Kulkarni

Chemistry and Physics of Materials Unit and Thematic Unit on Nanochemistry, Jawaharlal Nehru Centre for Advanced Scientific Research, Jakkur P.O., Bangalore 560064, India

[**] This work was supported by the European Commission's FP7 ICT Framework projects titled ROTROT (grant no. 288565) and HiFlex (grant no. 248678). Partial support was received by EU-Indian FP7 Framework project titled "LargeCells (grant no. 261936) (Supporting Information is available online from Wiley InterScience or from the author). processing, and operation- and maintenance-cost. Costreduction of polymer solar cells (PSCs) is envisioned through extremely fast processing via ambient roll-to-roll (R2R) printing and coating methods and using low-cost materials. In addition to cost reduction, PSCs ought to sustain several years of operational and storage conditions to be useful in real world applications. Previously, we have reported a completely scalable and efficient indium tin oxide (ITO)-free PSC arrived at through a process known as IOne which is a completely ambient process employing only coating and printing methods on a roll-to-roll production line. ${ }^{[1]}$ IOne modules display $>1.5 \%$ efficiency with a P3HT:PCBM system and is estimated to represent an energy payback time (EPBT) of $<2$ months in the form of the thin foil (mounting etc. may increase the EPBT). Such a technology will bring PSCs on par with silicon solar cells in terms of energy return factor with a lifetime as low as 2 years. With this feat which has now been developed into many incarnations including the first PSC park, ${ }^{[2]}$ it now becomes essential to focus on the stability of these solar cell modules under operational and storage conditions. It goes without saying that stability has direct implications on the application-, cost-, and environmentaleffectiveness of the technology. 
In general, stability of PSCs have been reported under various laboratory conditions ${ }^{[3-10]}$ but very few reports are present that deal with real-world operational and storage stability of PSCs modules ${ }^{[1,11,12]}$ especially in its commercially envisioned form that includes ITO-free flexible substrates. Degradation of PSCs can be complex with several mechanisms at play. In general, three distinctions can be made with regard to the overall stability of a PSC technology as schematically illustrated in Figure 1. At the core of PSC is the inherent stability of semiconducting/photoactive polymer. The photoactive polymers decay when subjected to chemical and physical stresses. In poly(3-hexylthiophene-2,5diyl) (P3HT) films, the most understood polymer in terms of degradation factors, photo-oxidation is the prominent degradation mechanism ${ }^{[13-16]}$; the addition of environmental conditions such as oxygen, humidity, and ozone can significantly accelerate the rate of photo-oxidation. ${ }^{[14]}$ Physical stresses, on the other hand, are more relevant to the mechanical handling of a finished product and can induce failure or loss in performance in a solar cell due to bending under tension or compression, shear stress, delamination etc. ${ }^{[17-20]}$ Interfacial mechanical stress may also be induced intrinsically due to, for example, morphological evolution of the photoactive polymer. ${ }^{[8]}$

Encasing the photoactive layer of the solar cells involves other materials and processes that influence performance. Apart from the photoactive material, metals used for electrodes can decay due to oxidation as well as due to various organo-metallic chemistry. ${ }^{[20-23]}$ Previously, we have evaluated several different architectures using the same encapsulation method and the same photoactive material under various rigorous accelerated testing conditions. Large differences in the stability of the solar cells were found attributable to electrode materials and processing of the solar cells. ${ }^{[24]}$ In all, every material component play a crucial role in determining the overall stability of a complete solar cell. In an uncontrolled aging environment, a combination of several or all of these degradation mechanisms is likely to take place.

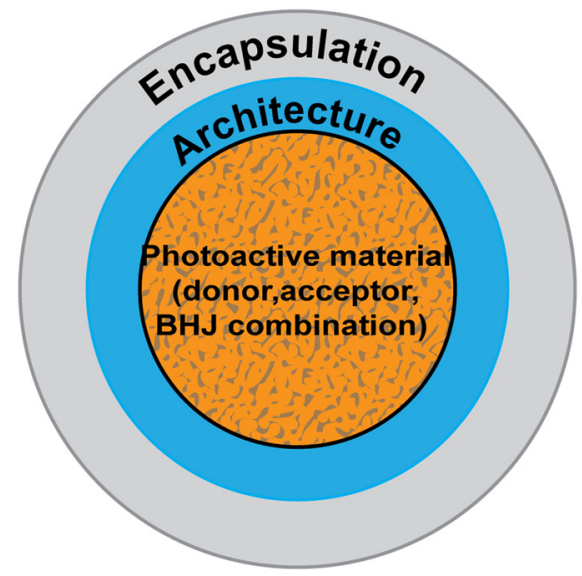

Fig. 1. Classification of material systems and their inter-relationships with regard to stability of an organic solar cell is schematically shown. Encapsulation, as addressed in this paper, is the overarching stability rendering component, which has seldom been investigated in organic solar cells.
Finally, the last but the most critical material that renders stability to an application-ready PSC is the encapsulation. While much is understood on the degradation factors in PSCs, ${ }^{[25,26]}$ very little has been done to demonstrate how these degradation factors can be prevented while PSCs are applied to real world operational and storage conditions. The answer of course is in the encapsulation. Yet, very few reports are present that deal with the encapsulation of PSCs. ${ }^{[27-30]}$ PSCs require encapsulation with a barrier material having low transmission rates of water vapor (WVTR) and oxygen (OTR). Moreover, the barrier material and encapsulation method should satisfy the technological goals of PSCs which includes transparency, flexibility and processibility with low-cost materials and processing techniques such as coating or lamination.

Given these requirements, we report on the outdoor operational performance of low-cost ITO-free modules encapsulated in a simple food packaging barrier film. The ITO-free IOne modules are studied in an interlaboratory setting in three climatically different countries. The purpose of this study was to evaluate the stability as well as to study the impact of differences in the climatic conditions on the stability of the modules under the current encapsulation scheme.

\section{The Polymer Solar Cell Module and Encapsulation}

The modules tested were based on an ITO-free architecture, known as IOne, extensively reported elsewhere. ${ }^{[1]}$ The module geometry, layer stacking, and the encapsulation scheme are shown schematically in Figure 2. The IOne modules are fabricated in an ambient roll-to-roll process using coating and printing methods as detailed in the experiment section (Section 5). Encapsulation was achieved by laminating the modules between two sheets of the barrier foil with the use of a UV curable adhesive and subsequently exposing them to UV light under a solar simulator to cure the adhesive. Contacting is achieved by punching push buttons through the encapsulation over the copper tape as schematically shown in Figure 2 as well.

\section{Results}

The modules were tested under real world outdoor operational conditions (ISOS-O) according to protocols laid out by the international summit on OPV stability (ISOS-3). ${ }^{\text {[31] }}$ Two variants of the modules were tested. In the first generation (Gen-I), the substrate was a PET barrier foil of $45 \mu \mathrm{m}$ thickness. In the second version (Gen-II), the substrate was $125 \mu \mathrm{m}$ thick PET foil. The Gen-I modules were evaluated in an interlaboratory stability test conducted simultaneously in India (ISOS-O-2) and in Denmark (ISOS-O-3); while the Gen-II modules were tested simultaneously in Netherlands (ISOS-O-1) and Denmark (ISOS-O-3). The Gen-II modules were also investigated for stability under storage (ISOS-D-1). The different testing set-ups for outdoor operation are shown in Figure 3. All modules were initially characterized in 


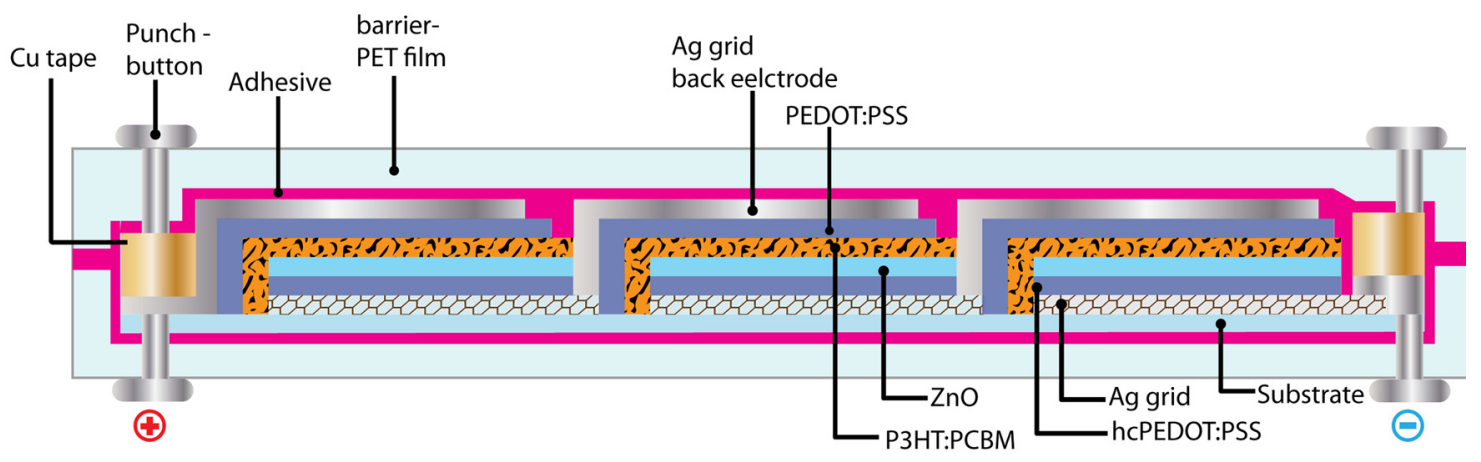

\section{Top view}

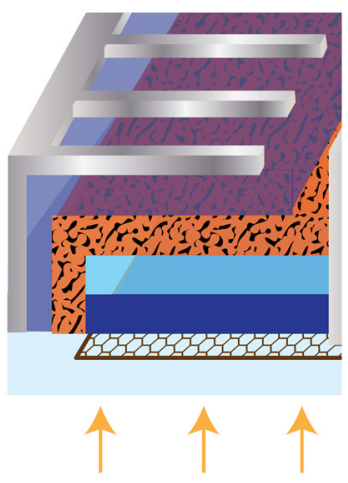

Encapsulation

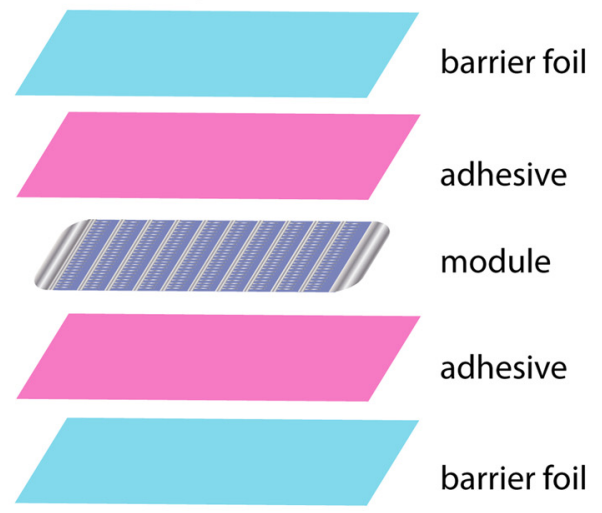

Fig. 2. Schematic illustration of the ITO-free IOne modules. The encapsulation scheme as well as the top view of the module is depicted. Arrows show the direction of illumination.

Denmark under a solar simulator equipped with a sulfur plasma lamp having a class A spectrum in the absorption range of the photoactive material. Prior to each measurement rounds, the lamp was calibrated using a reference photodiode to supply 1 sun illumination ( $1000 \mathrm{~W} \mathrm{~m}^{-2}$; AM $\left.1.5 \mathrm{G}, 60^{\circ} \mathrm{C}\right)$. At the end of the stability measurement, all modules were collected back in Denmark and measured under the same solar simulator. The data of all the modules before and after the tests can be found in Table 1. Details on the measurement set-up are given in Section 5.

\subsection{Denmark-India Interlaboratory Study}

Figure 4 demonstrates the degradation pattern of all IV parameters of the two IOne Gen-I modules studied in Denmark. The modules were tested for a duration exceeding 1 year ( 10 $000 \mathrm{~h})$. The IV parameters are normalized to the initial performance (at $t=0$ ) which was during the mid-day in mid-summer when the irradiance was above $900 \mathrm{~W} \mathrm{~m}^{-2}$ at AM $1.5 \mathrm{G}$. Measurements were automatically recorded every $15 \mathrm{~min}$ and the scatter plot reflects the variation in the module photovoltaic performance in accordance with the day and night cycle. Furthermore, the variation in the performance of the modules during the seasons can also be distinguished with respect to the irradiance.
If the modules have not degraded, the maximum power point (MPP) would have recuperated after the end of winter such that the measurements in June 2013, for example, would have been similar to the measurement made in June of 2012. However, both modules have degraded over the testing duration of $>1$ year and is also attested by the intermittent measurements carried out under solar simulator providing constant 1 sun illumination (Figure 4). A lifetime (T80), which is defined as the time it takes the module to degrade to $80 \%$ of its peak performance, of $1000-1500 \mathrm{~h}$ can be deduced. Degradation of one of the modules (DK-N14) is characterized by declining short circuit current $\left(I_{\mathrm{sc}}\right)$ while open circuit voltage $\left(V_{\mathrm{oc}}\right)$ is not affected and fill factor (FF) is less affected (above $95 \%$ of initial FF). The second module (DK-N13) is characterized by declining of all IV parameters: $I_{\mathrm{sc}}, V_{\mathrm{oc}}$ and FF (Figure 4). The underlying cause of degradation in both the modules is the same albeit at different extent of severity. The degradation is mainly dictated by delamination and degradation of PEDOT:PSS which also induces enhanced localized photo-oxidation. This is detailed henceforth.

Figure 5 shows photographs of the DK-N13 and DK-N14 modules with strong backlighting taken after the end of the outdoor test. A visible discoloration or bleaching in the end cell of module DK-N13 is observed which suggest oxygen and 

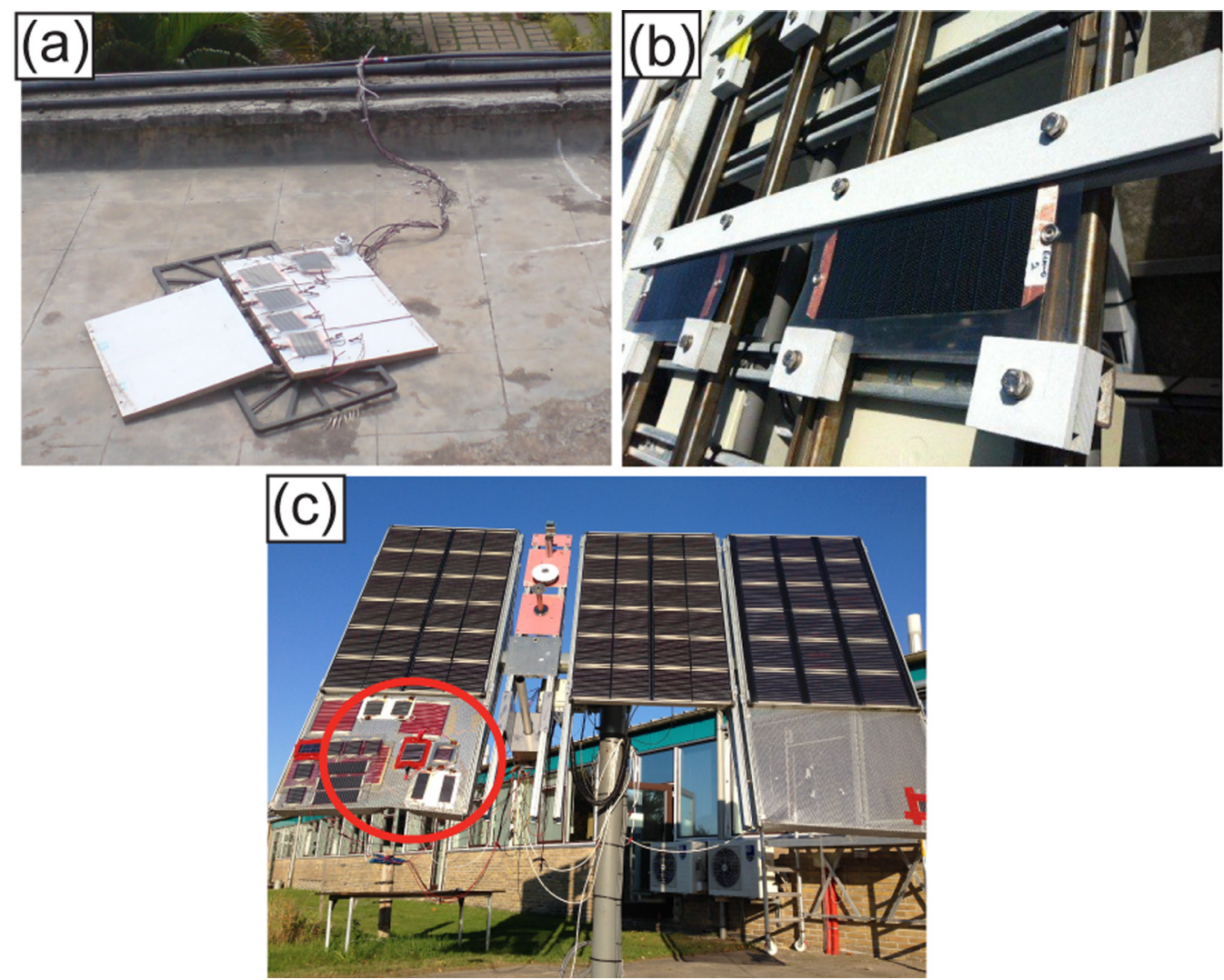

Fig. 3. Set-up for outdoor testing: (a) The rooftop stationary set-up at $5^{\circ}$ inclination facing South at Bangalore, India (a); rooftop stationary set-up at ECN, Netherlands (b); the modules (red circled) on a tracker at Roskilde, Denmark (c).

moisture infiltration leading to accelerated photo-oxidation of the adjacent cells to the contacts in the module. This is plausible as the push-buttons are punched through the encapsulated module. Often, this inadvertently leads to encapsulation flaw exposing the cross-section of the encapsulation around the push-button, which lie very close to the active part of the module. At the cross-section, the adhesive is also exposed to ambient conditions. The adhesive is not a barrier material and has WVTR significantly higher than the barrier foil (WVTR of $1 \mathrm{~mm}$ thick DELO Katiobond LP655 is $6 \mathrm{~g} \mathrm{~m}^{-2}$ day $^{-1}$ ) and as such the exposed adhesive around the contact provides an easy passage for rapid moisture and oxygen diffusion into the module causing enhanced degradation of the first cell adjacent to the contact. However, once the cell adjacent to the contact is completely degraded, the module starts behaving like a six-cell module (instead of

Table 1. The photovoltaic properties of all reported modules measured before and after the stability tests under $1 \mathrm{sun}\left(1000 \mathrm{Wm} m^{-2} \mathrm{AM} 1.5 \mathrm{G} 60^{\circ} \mathrm{C}\right)$.

\begin{tabular}{|c|c|c|c|c|c|c|c|c|c|}
\hline \multirow[b]{2}{*}{ Module ID } & \multicolumn{3}{|c|}{ Before $(t=0)$} & \multirow[b]{2}{*}{$\mathrm{FF}[\%]$} & \multirow[b]{2}{*}{ MPP [mW] } & \multicolumn{3}{|c|}{ After $\approx 1$ year } & \multirow{2}{*}{$\begin{array}{l}\text { Change in } \\
\text { MPP [\%] }\end{array}$} \\
\hline & $\mathrm{MPP}[\mathrm{mW}]$ & $V_{\mathrm{oc}}[\mathrm{V}]$ & $I_{\mathrm{sc}}[\mathrm{mA}]$ & & & $V_{\mathrm{oc}}[\mathrm{V}]$ & $I_{\mathrm{sc}}[\mathrm{mA}]$ & FF $[\%]$ & \\
\hline \multicolumn{10}{|c|}{ GEN-I (ISOS-O) } \\
\hline DK-N13 & 97.00 & 3.57 & 46.25 & 58.81 & 22.21 & 2.42 & 30.37 & 30.17 & -77 \\
\hline DK-N14 & 108.17 & 3.57 & 53.89 & 56.15 & 28.52 & 3.42 & 16.71 & 49.91 & -74 \\
\hline IN-N02 & 107.17 & 3.57 & 51.40 & 58.46 & 5.61 & 2.20 & 10.36 & 24.60 & -95 \\
\hline IN-N05 & 90.73 & 3.53 & 52.03 & 49.41 & 8.61 & 3.18 & 9.71 & 27.91 & -91 \\
\hline \multicolumn{10}{|c|}{ GEN-II (ISOS-O) } \\
\hline DK-N01 & 85.99 & 5.53 & 28.58 & 54.39 & 95.54 & 5.62 & 30.65 & 55.45 & +11 \\
\hline DK-N02 & 84.55 & 5.58 & 27.92 & 54.27 & 4.73 & 4.02 & 4.81 & 24.08 & -94 \\
\hline NL-N11 & 93.63 & 5.50 & 30.42 & 55.91 & 70.82 & 5.02 & 28.46 & 49.55 & -24 \\
\hline NL-N12 & 90.56 & 5.47 & 29.89 & 55.41 & 76.49 & 5.50 & 28.53 & 48.72 & -15 \\
\hline \multicolumn{10}{|c|}{ GEN-II (ISOS-D-1) } \\
\hline DK-N02 & 83.14 & 5.49 & 28.62 & 52.97 & 81.73 & 5.42 & 30.42 & 49.55 & -1 \\
\hline NL-N09 & 94.51 & 5.57 & 29.76 & 57.01 & 79.12 & 5.50 & 28.76 & 49.99 & -16 \\
\hline
\end{tabular}



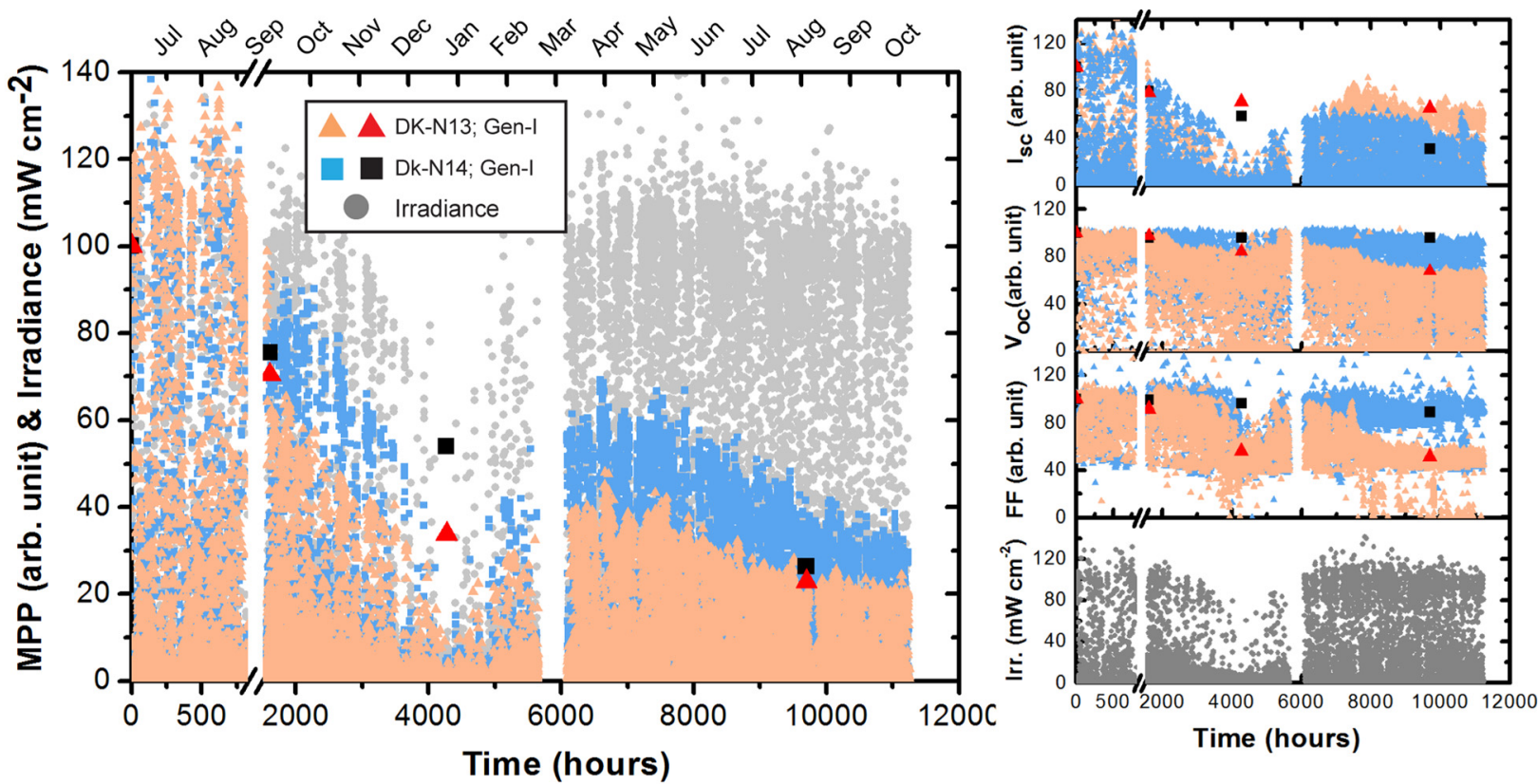

Fig. 4. Performance of a GEN-I module under outdoor conditions in Denmark (DK) measured for a duration of $9696 \mathrm{~h}$. The data is normalized to initial performance at $T=0$. The scatter plot (red and black symbols) shows the intermittent measurements conducted under a solar simulator at $1000 \mathrm{Wm} \mathrm{m}^{-2} \mathrm{AM} 1.5 \mathrm{G} 60^{\circ} \mathrm{C}$ which correspond well with the data observed under real outdoor conditions.

seven cells originally) and the end cell acts like a resistor hampering charge transport from the rest of the module to the external contact. As the degradation agents diffuse into the second cell from the defective contact, $I_{\mathrm{sc}}$ degrades while $V_{\mathrm{oc}}$ and FF remain intact. The trend continues until the whole second cell is degraded upon which $V_{\mathrm{oc}}$ and FF will start to degrade and the cycle continues.

The extent of degradation in each cell and the variation of degradation across the cells in the module DK-N13 can be evidenced under an optical microscope in transmission mode as these regions are marked by high density and different sizes of photo-oxidized regions that appears as distinctly discolored or bleached spots. The cell adjacent to the contact shows the highest degree of photo-oxidation while the subsequent cells in-line shows a decreasing level of the degradation. Such spots are not present in the center of the module or in a freshly prepared module (Figure 6). Such
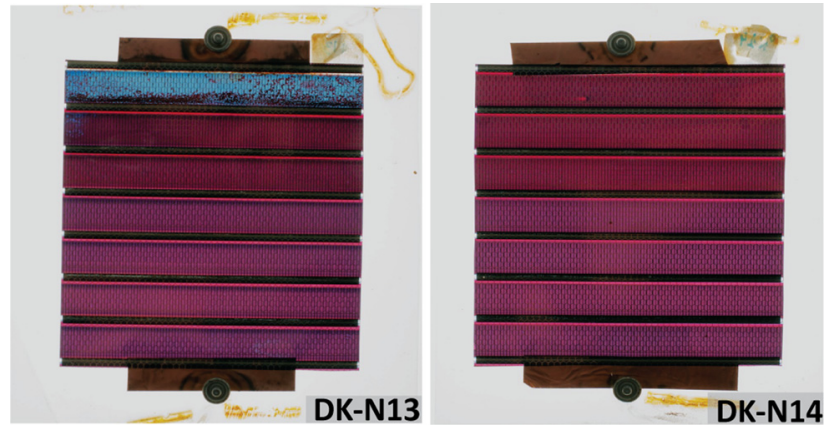

Fig. 5. Images of the serially-intergrated modules, each with several cells, after being tested under outdoor conditions (ISOS-O) in Denmark. The active area is $70 \mathrm{~cm}^{2}$. pictorial evidences of photo-oxidation in a PSC stack have not been reported earlier; inferences have been mostly based on the decay trend in the photovoltaic parameters upon ageing or deduction by other techniques such as luminescence imaging. ${ }^{[28,32]}$ Optical imaging of photo-oxidation is not possible in a conventional normal or inverted device stack which usually has an opaque layer, the non-transparent metal electrode. Such imaging is only possible in a semi-transparent solar cell or if the back metal electrode can be removed after testing. Furthermore, we observed that it is not possible to view these photo-oxidized regions in either bright field or dark field optical imaging techniques.

While visible bleaching is not seen in module DK-N14, the degradation trend of its $I_{\mathrm{sc}}$ suggests that the module has

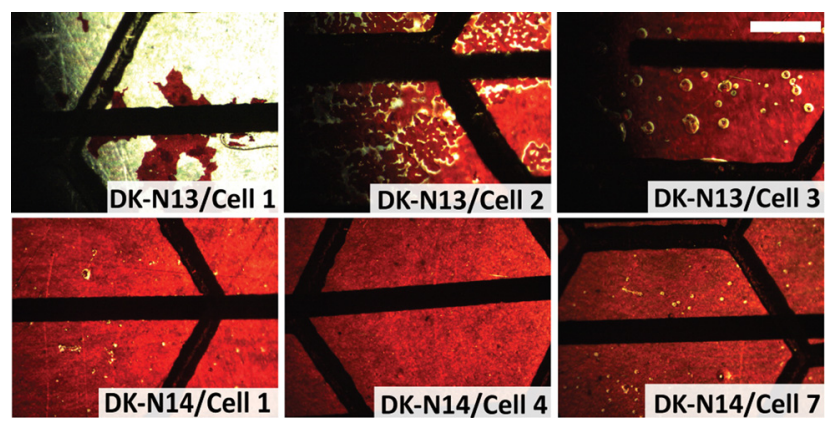

Fig. 6. Optical images of the two modules, DK- N13 and DK-N14, in transmission mode showing the degree of photo-oxidation. The images are taken after $10000 \mathrm{~h}$ of outdoor testing (ISOS-O-3). Note that for module DK-N14, the photo-oxidation does not correspond with the degradation observed under LBIC images (Figure 7), which suggest that localized photo-oxidation is not the main cause of degradation in performance. 

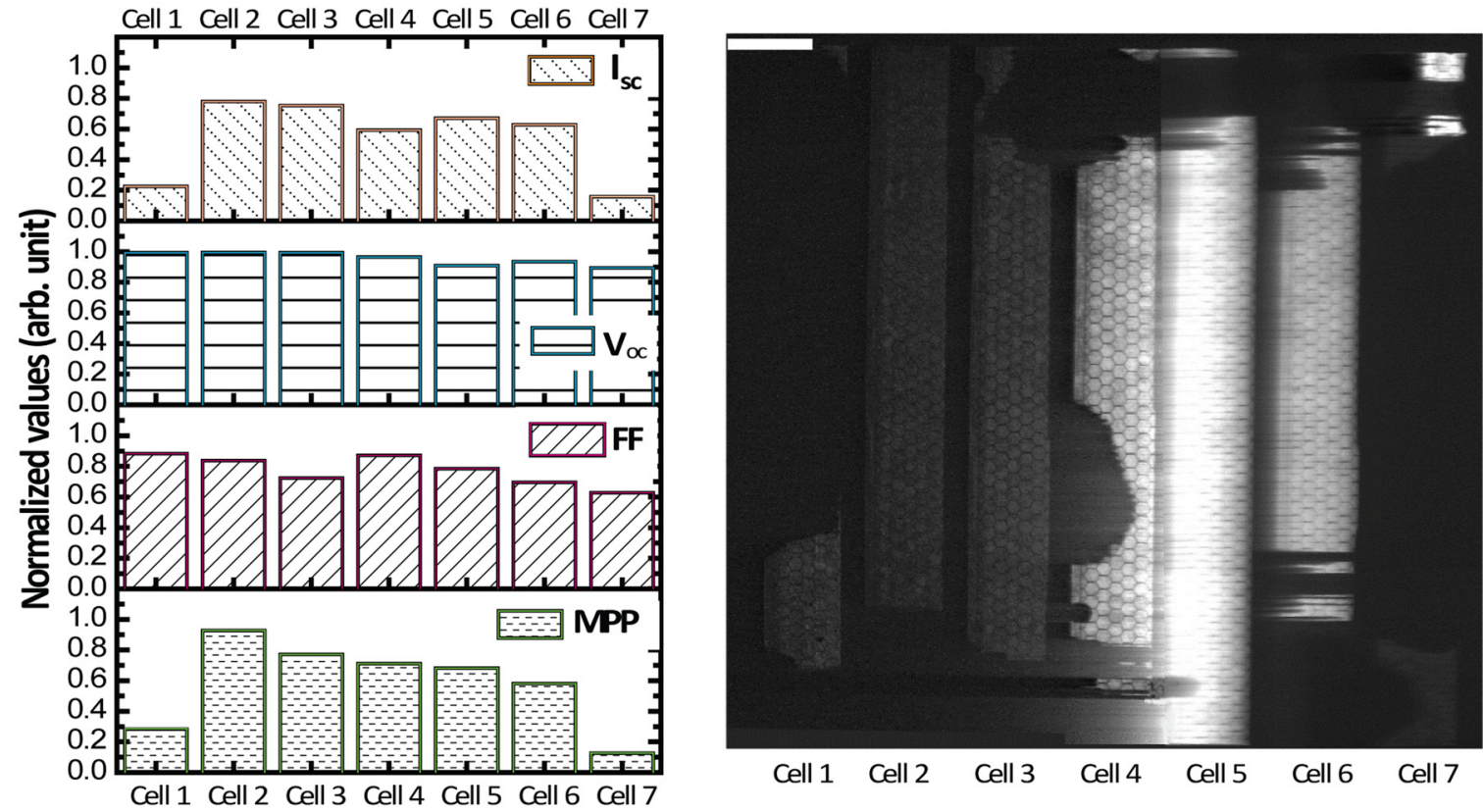

Fig. 7. The bar graph on the left shows the performance of each cell in the module DK-N14 after $>1$ year of outdoor operational stability (ISOS-O-3) testing conducted in Roskilde, Denmark. The module is comprised of seven interconnected cells, each of $1 \mathrm{~cm} \times 7 \mathrm{~cm}\left(7 \mathrm{~cm}^{2}\right)$ active area. An LBIC image of the same module is shown on the right. The cells are numbered from 1 to 7 with cell 1 corresponding to the cell adjacent to the positive contact and cell 7 to the negative contact. The scale bar corresponds to $1 \mathrm{~cm}$.

suffered a more severe degradation than DK-N13 (Figure 4). However, the optical images do not reveal conclusive results since the density and number of oxidized regions is very few (Figure 6) which does not correspond with the rapid decay in current, unlike in DK-N13.

In order to investigate the cause of degradation of DK-N14, a second method of degradation analyses was used by simply recording the IV curves of the individual cells in the module after the test. This was accomplished with the use of a needle to pierce through the barrier and establish contact. ${ }^{[12]}$ In this way, each cell in the module could be individually characterized for IV properties. Figure 7 shows the variation of each cell after the outdoor test period of $\sim 10000 \mathrm{~h}$ in module DK-N14. All parameters are normalized to the initial values of the whole module recorded under solar simulator at $1000 \mathrm{~W} \mathrm{~m}^{-2}$ AM1.5G. Such a method is viable in a serially-integrated module because the current of the module is a close to the average of the currents of all the cells (provided that they all perform similarly) while $V_{\text {oc }}$ of the module is the sum of each cell in the module. Hence, both $I_{\mathrm{sc}}$ and $V_{\mathrm{oc}}$ of the module can be referenced with respect to each individual cell in the module. However, FF has no such relation as it is resistance and current dependent and also the manual contacting method with a needle source may hamper FF and therefore normalization of FF to that of the whole module is the least reliable parameter. Therefore, the cells in the module must be evaluated with regard to $I_{\mathrm{sc}}$ and $V_{\mathrm{oc}}$.

As it can be seen in Figure 7, the end cells of DK-N14 (cell 1 and cell 7) show the highest loss in $I_{\mathrm{sc}}$ while $V_{\mathrm{oc}}$ of all the cells is still performing above $90 \%$ of the initial $V_{\mathrm{oc}}$. The rest of the cells display various ranges of loss in $I_{\mathrm{sc}}$ and is attributed to various degrees of delamination and/or degradation of the PEDOT:PSS hole transport layer (HTL). In order to verify the role of PEDOT:PSS HTL, a combination of LBIC imaging and optical images can provide useful information. LBIC imaging utilizes a laser beam to raster scan a module or a solar cell and the current thus generated in the solar cell is imaged highlighting defects that do not contribute to current generation/transport. As can be seen in the LBIC image given in Figure 7, nearly all cells have some areas that are still active. This is the reason that $V_{\mathrm{oc}}$ remains nearly intact in all the cells as seen in the bar graph. However, all cells have suffered various degrees of localized degradation. Cell 7 displays the highest loss of photoactive area with a tiny region that is still operational, closely followed by cell 1 . Both cell 1 and cell 7 are the end cells adjacent to the positive and negative contacts in the modules, respectively. The LBIC image is in accordance with the $I_{\mathrm{sc}}$ trend shown in the bar graph (Figure 7). Despite the large current inhibited regions, cell 1 and cell 7 when imaged under optical microscope only show a few scattered and small spots of photo-oxidized regions (Figure 6). Hence, it can be inferred that photooxidation of the photoactive polymer is not the primary reason for degradation, but the localized degradation is due to delamination or degradation of the top PEDOT:PSS holetransport layer which hampers charge transport. PEDOT:PSS is particularly susceptible as it has a large surface area that lie in direct contact with the adhesive (shown schematically in Figure 2, top view). Since the adhesive does not bear any barrier properties and is exposed to ambient conditions at the defects introduced by the contacts, it provides an easy and a short passage to water and oxygen diffusion into the end cells 
of the module. Moreover, PEDOT:PSS is highly hygroscopic which results in a change of conductivity upon water uptake. ${ }^{[33-35]}$ Furthermore, the PEDOT:PSS HTL also has a very low adhesion strength with the photoactive polymer. ${ }^{[36]}$ All these factors may lead to a combination of delamination and degradation of PEDOT:PSS. Making a distinction between the two is not possible at this point. It is to be further noted that the barrier foil employed in encapsulating the module has a UV filter which allows $<2 \%$ of UV light below $390 \mathrm{~nm}$. UV light is crucial and is the primary reason for photo-oxidation of P3HT while the addition of other degradation agents such as water, oxygen, and temperature may accelerate the rate of degradation. Hence, despite the very low permitted UV light, the water and oxygen that is conducted into the device via the defects from the contacting method have resulted in the enhanced photo-oxidation in the end cells in DK-N13 whereas photo-oxidation is not the primary reason for degradation in module DK-N14.

In DK-N14, cell no. 2 is the best performing with a PCE of $1.01 \%$. While $1 \%$ is significantly higher than then efficiency of the total module after the test $(0.28 \%)$, yet it is far from initial efficiency of the module of $1.6 \%$. The lack of edge sealing may have caused enhanced localized degradation around the edges of the module. As it can be observed in the LBIC image in Figure 7, the edge of the cell 2 is inactive (an area that comprise more than one-fifth of the total area of the cell). Similarly, defects seem to be propagating from the edges apart from the contacts for most cells in the module. Furthermore, in areas where the adhesive is thicker, the grooves in the surface of the solar cells which are present around the solar cell and in between the cells over the interconnection region (also

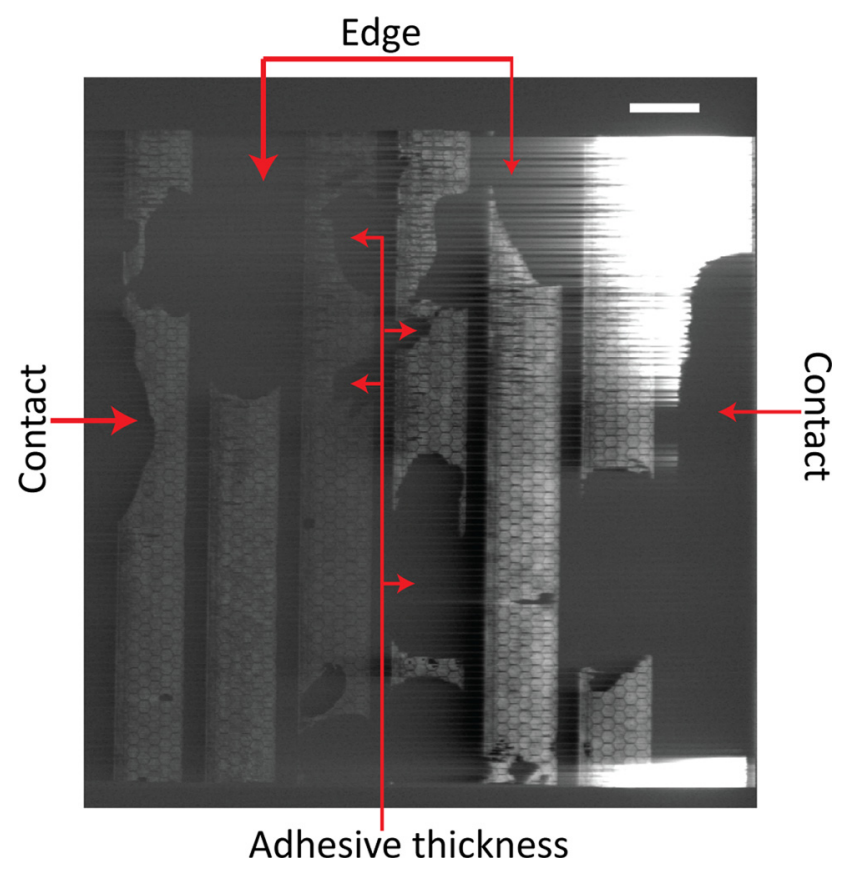

Fig. 8. The common defects observed in Gen-I modules studied under outdoor operational stability in Denmark and India. The image is recorded on a module tested in India (IN-05). schematically discernible in Figure 2), appears to be propagating defects in the modules. This is particularly visible as defects that seem to initiate in the middle of the module away from both the contacts and the edges. At this point, the origin of the defects is not distinguishable, that is, if they originate from a point source (the contacts) and propagates through the edges where the adhesive has higher thickness or if they are independently initiated from the edges. However, it will become clear in the next section. All three types of defects can be distinguished in Figure 8.

The Gen-I modules tested in India display a very similar degradation pattern of the photovoltaic parameters to the counterparts measured in Denmark (Figure 8 vs. Figure 3). The large climatic variation between India and Denmark with respect to temperature, humidity, and precipitation are observed to result in an average of $15 \%$ higher degradation in India in comparison to Denmark (Table 1). The LBIC and optical images of the module tested in India attest to the localized failures initiated from the contacts, edges, and from the grooves in the solar cells where the thickness of the adhesive is higher than on the planar surfaces (Figure 8). The climatic differences are given in the Supporting Information (Figure S-1).

\subsection{Denmark-Netherlands Interlaboratory Test (Gen-II Modules)}

\subsubsection{Outdoor Operational Stability}

The first set of outdoor stability experiments on Gen-I modules highlighted the issue of localized defects due to the contacts, edges, and the adhesive. These defects were an outcome of encapsulation shortcomings that include the proximity of the button contacts to the end cells in a module, narrow edge sealing margins, and the variation in the thickness of the adhesive layer. The former two issues can be alleviated by simple measures that include extending the edge sealing margins and having the button contacts away from the end cells of the modules; the latter in relation to the uneven adhesive layer may inadvertently be alleviated with the solving of the former two or it may require planarization of the topography of the solar cells with some material such that a thin outline of the adhesive can be maintained throughout the module. Any alteration in the placement of button contacts requires redesigning the modules with elongated main busbars- a topic of future study; however, the effect of increasing edge sealing margins can be readily studied. In the following, we report upon the effect of increasing edge sealing margins on the IOne modules.

A second generation of IOne modules (Gen-II) were encapsulated with larger edge sealing margins $(>1 \mathrm{~cm})$. Gen-II and Gen-I modules were similar in their structure with the only difference being in the type of the substrate (Gen-I employed $45 \mu \mathrm{m}$ thick barrier foil while Gen-II employed $125 \mu \mathrm{m}$ thick PET) and the edge sealing margin. The difference in edge sealing of Gen-I and Gen-II modules is illustrated in Figure 9. The modules were then studied for 


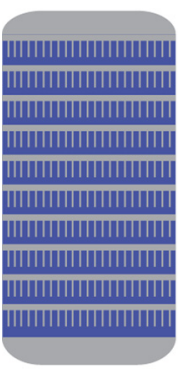

(a)

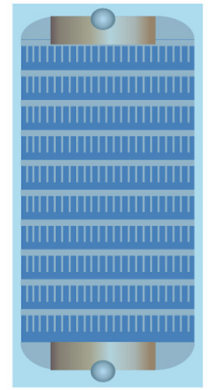

(b)

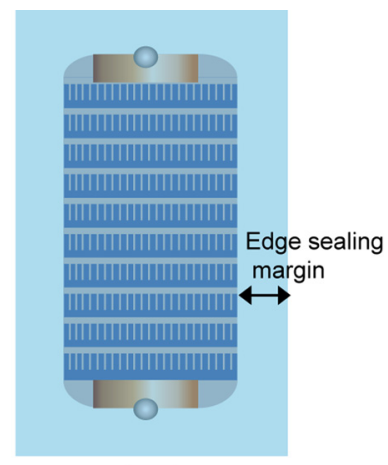

(c)
Fig. 9. An unencapsulated (a), Gen-I (b), and Gen-II (c) modules are schematically illustrated. The edge-sealing margin in Gen-II modules $(1 \mathrm{~cm})$ was larger than Gen-I modules.

outdoor stability at two different locations: DTU (Denmark) and ECN (Netherlands). The tests were started on October 03, 2012 at both locations and continued until October 09, 2013, resulting in a duration of $\sim 1$ year $(>8000 \mathrm{~h})$. Figure 10 shows the stability of the Gen-II modules tested in Netherlands which can readily be compared with the Gen-I modules displayed in the same Figure. Figure 11 shows operational stability of Gen-II modules tested in Denmark. The data is not normalized because the initial measurement was started in late October when the irradiance is lower than $800 \mathrm{~W} \mathrm{~m}^{-2}$ and does not represent the full performance of the modules. Nonetheless, the intermittent measurements conducted under a solar simulator at $1000 \mathrm{~W} \mathrm{~m}^{-2} \mathrm{AM} 1.5 \mathrm{G}$ provides standard measurement data which correspond well with the trend displayed by the outdoor measurements (Figure 11).
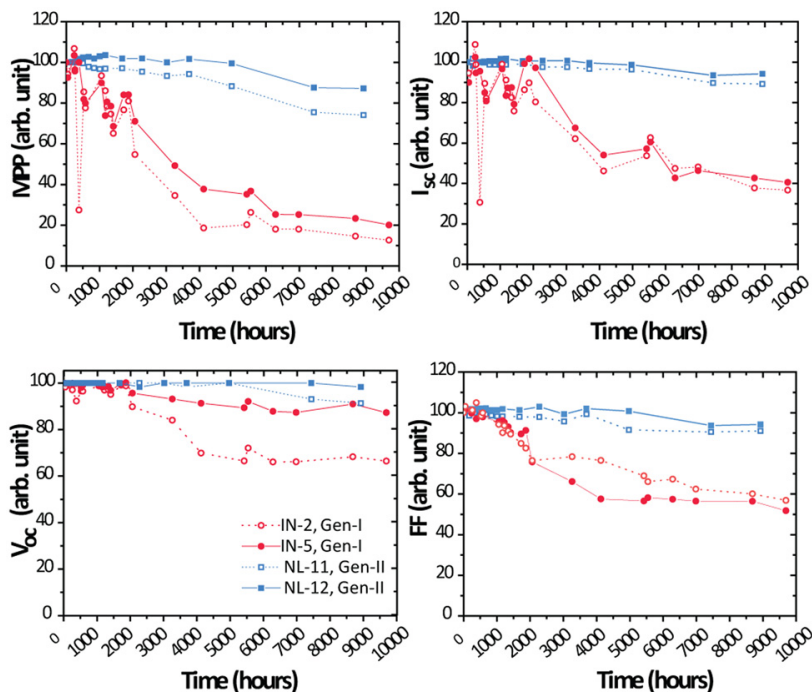

Fig. 10. Outdoor operational stability of Gen-I modules measured in India (IN) and Gen-II modules measured in Netherlands (NL). In India, modules were intermittently measured when the solar irradiance was above $800 \mathrm{Wm}^{-2}, A M 1.5 \mathrm{G}$ whereas the modules were intermittently measured under a solar simulator supplying $1000 \mathrm{Wm}^{-2}$ in Netherlands. The data of all modules are normalized to their respective initial measurement.

Gen-II modules display significantly improved stability when compared to the Gen-I modules. The MPP of the modules follow the trend in irradiance and temperature and is a direct outcome of variation in $I_{\mathrm{sc}}$. The best modules in both the Netherlands and Denmark are operating above T80 at the end of 1 year. In fact, the module in Denmark has not suffered any degradation at all as evident in the same first and the last intermittent measurements which were conducted in October 2012 and October 2013, respectively. Intriguingly, the
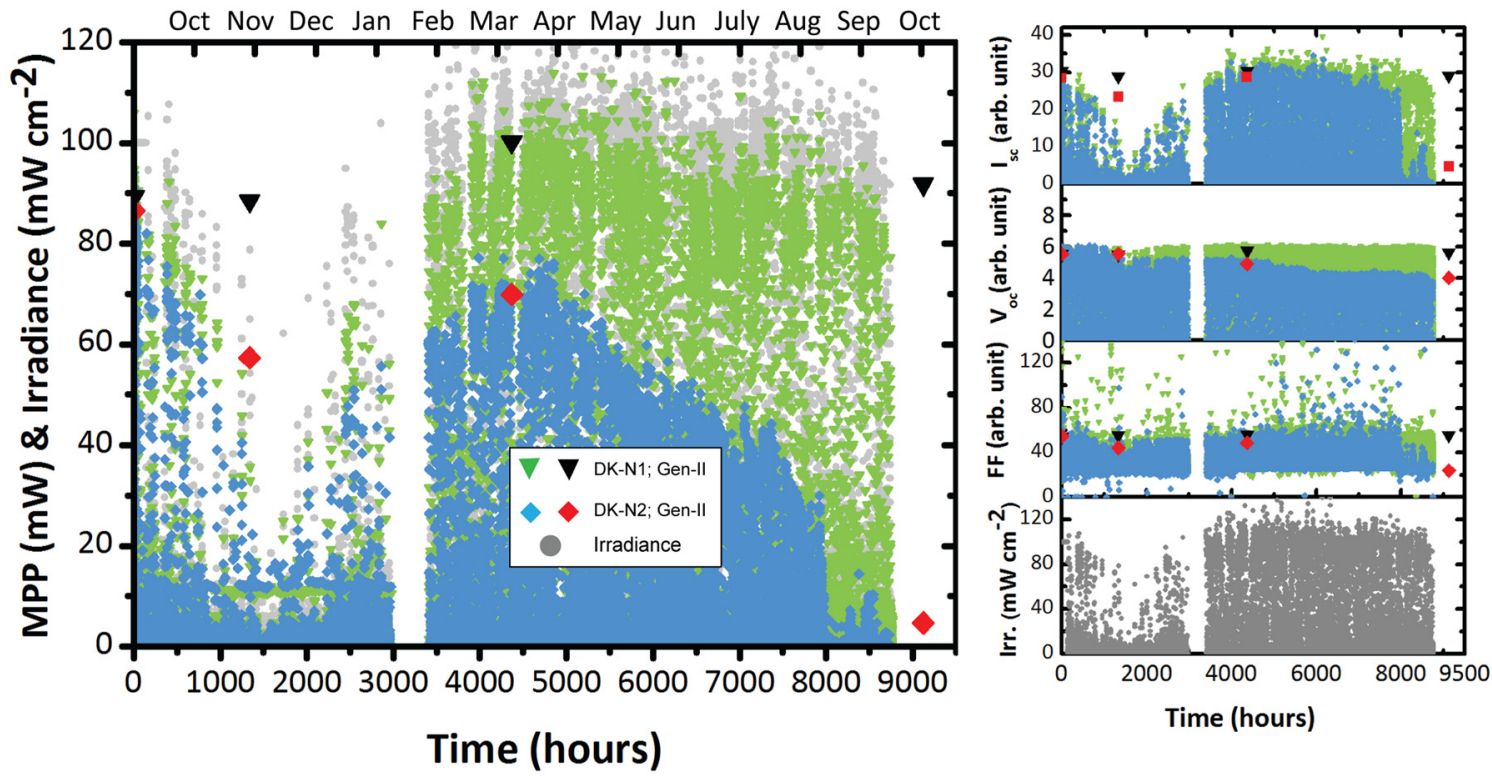

Fig. 11. Comparative stability of GEN-II modules tested in Roskilde, Denmark under outdoor conditions. The scatter plot in red diamonds and black inverted triangles show intermittent measurements under a solar simulator (1000 $\mathrm{Wm}^{-2}$; AM $\left.1.5 \mathrm{G}\right)$. 
intermittent measurement of modules tested in Denmark exhibit a $12 \%$ improvement with respect to the first indoor measurement despite being measured under the same controlled conditions ( 1 sun, $\mathrm{AM} 1.5 \mathrm{G} ; 60^{\circ} \mathrm{C}$ ) at all times. Most of this improvement comes from an increase in $V_{\text {oc }}(4 \%$ increase) and FF ( $3 \%$ increase) while $J_{\mathrm{sc}}$ improves negligibly $(0.012 \%$ increase). Generally, temperature negatively impacts $V_{\mathrm{oc}}$ and positively enhances $I_{\mathrm{sc}}$ which is attributed to temperature dependence of charge mobility due to thermal activation of charge mobility in a bulk heterojunction system. ${ }^{[37]}$ In the Gen-II modules, the increase in $V_{\mathrm{oc}}$ is expected to be an outcome of the PEDOT:PSS layers whose electronic properties (work function and conductivity) is known to be highly variable with temperature and humidity. ${ }^{[34]}$ The modules when measured intermittently under the solar simulator are let to equilibrate (light soaked under the solar simulator) for only 5 min after taking them down from the solar tracker. This duration may not be sufficient to remove the "memory effect of several months of outdoor exposure. Therefore, after prolonged exposure in the peak summer season with high irradiation and temperature along with low precipitation allows the PEDOT:PSS to increase conductivity and work function which could explain the increase in $V_{\mathrm{oc}}$ and FF, without significantly changing $I_{\mathrm{sc}}$.

Overall, the degradation pattern of Gen-II modules confirm that increasing the edge sealing margin without changing the
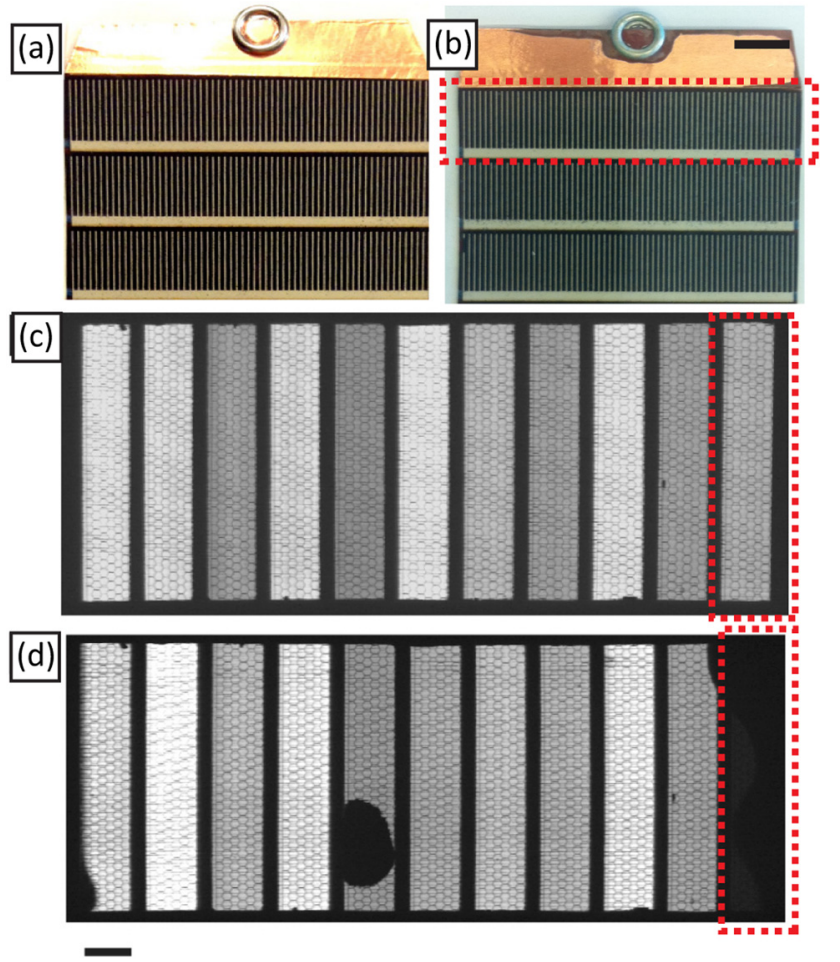

Fig. 12. The negative contact of a Gen-II module is shown before outdoor testing (a) and after 1 year of outdoor operation (b). Oxidation of the contact can be clearly distinguished in (b). LBIC image of the same module before (c) and after (d) the outdoor test which shows that only contact leads to failures in the end cells while edges of the in-between cells remain unaffected. Same trend is observed in all Gen-II modules. The defect in the middle is due to a scratch in the barrier foil. distance of contact to the active of the module dramatically enhances stability. This leads to the conclusion the edges operate independently of the defective contacts to allow degradation agents into the device. It must be noted that the adhesive around the perimeter of the encapsulated module is directly exposed to the ambient conditions and has a significantly larger cross-sectional area than around the contacts. By increasing the edge sealing margin as was done for Gen-II modules, the net effective diffusion length of the degradation agents to the active part of the module is much higher than in Gen-I modules. Edge sealing by $1-2 \mathrm{~cm}$ seems to be sufficient for $>1$ year of outdoor operational stability. Now, the degradation of all Gen-II modules is determined only by defects originating from the contacts. Figure 12 shows a picture of the contact of a Gen-II module that shows oxidation of the button contact as well as the surrounding copper tape. The corresponding LBIC image shows that only the cells adjacent to the contacts have degraded while all the in-between and especially the edges of all the cells remain intact. Particularly, the cell adjacent to the negative contact appears to degrade faster than the one close to the positive contact. This could be due to the fact that there is a groove between the negative contact and the end cell solar cell which is filled with the adhesive as it is evident in Figure 2 as well. Such grooves where the thickness of the adhesive is higher act as reservoir for degradation agents, particularly moisture. Finally, the large spread in the amount of degradation in Gen-II modules is due to the manual contacting method which introduces different amount wear and tear and delamination around the button contact. Particularly, module DK-N2 demonstrated contact failure already at $1000 \mathrm{~h}$ of operation while all other modules were not affected by that time. Nevertheless, irrespective of the spread in the data, it remains clear that Gen-II modules suffer degradation only primarily due to the contacts.

\subsubsection{Shelf-Life (ISOS-D-1)}

Shelf-life or storage is most critical during the lag time between production and consumption. One can imagine that this time for PSCs could range anywhere between 2 and 5 years or more. Ideally, a solar cell should not degrade at all under storage conditions. Figure 13 shows the storage stability of Gen-II modules. Both modules evaluated in the Netherlands (NL-N9) and Denmark DK-N2) are operating above their lifetime T80 after 1 year. The decay trend in $I_{\mathrm{sc}}$ and $V_{\text {oc }}$ suggest that both modules remain stable up-to $10000 \mathrm{~h}$ and the loss observed in MPP is a result of decaying FF. Similar to the trends observed in the ISOS-O Gen-II modules, the modules when analyzed under LBIC revealed that the devices fail near the contacts owing to moisture uptake by PEDOT:PSS which only impacts FF. It is noteworthy that the net degradation of the modules tested in the Netherlands under storage (NL-09) and outdoor operation (NL-12) exhibit very similar net degradation over 1 year, which is a testament to the robustness of the encapsulation materials. Pending successful resolution of the issue with contacting, the 

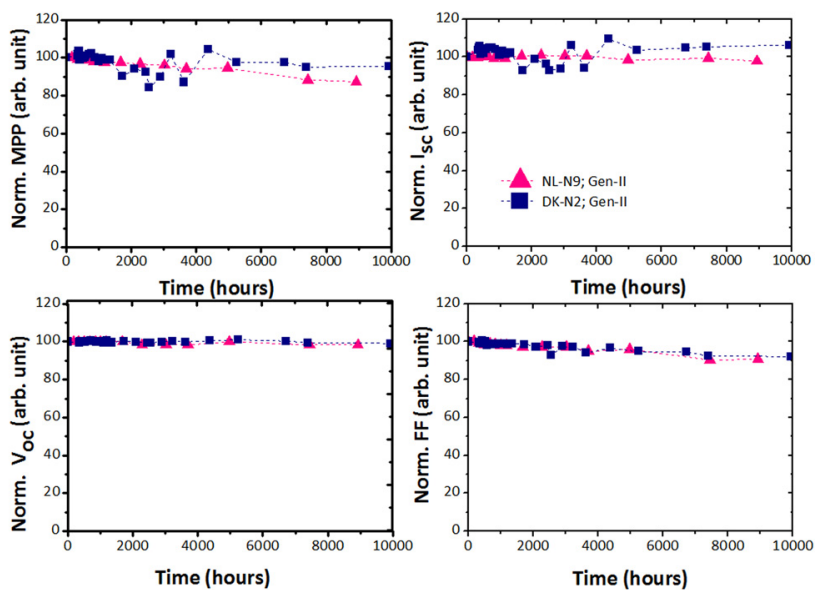

Fig. 13. Storage stability of Gen-II modules investigated simultaneously in Netherlands and Denmark.

encapsulation scheme used in this study may prove highly successful as a low-cost method. Note that the encapsulation scheme is fully compatible with several roll-to-roll techniques as our group has recently demonstrated. ${ }^{[38]}$

\section{Conclusion and Future Work}

Accelerated testing under a variety of accelerated storage and operational conditions have been proposed under the ISOS test protocols which may shorten the otherwise impractical duration required for stability analysis of solar cells. However, generally only one or two selected tests are reported for PSCs which never gives a conclusive picture about the real world stability of solar cells. We recognize the need to define a standard protocol for predicting stability of solar cells which must incorporate a holistic test under humidity, temperature, and irradiation. At this juncture, no such standards for lifetime determination of PSCs exist. In the absence of such a protocol, the best way to know the lifetime and long term failure mechanisms of modules is to evaluate them under real world operational and storage conditions.

In our specific tests reported in this study, the outdoor testing provides an accurate estimate of real world operation and stability of the IOne modules. Furthermore, the interlaboratory testing gives confirmation on the robustness and reproducibility of the performance of the IOne modules. All studies conducted in the Netherlands, Denmark, and India reveals that encapsulation has to be improved with regard to the contacting scheme as well as edge sealing.

This is particularly essential when the solar cell has a PEDOT:PSS layer inside. Ideally, replacing PEDOT:PSS altogether with a more stable printable hole-transport layer may significantly alleviate the problem; however there are currently no viable alternatives that are fully compatible with all-solution ambient R2R processed PSC modules. With regard to contacts, the button contacts are a facile method, however they ought to be improved. One possible way to improve is by use of a copper ribbon such that the contacts can be applied away from the active part of the modules or even outside the modules. Improved copper tapes have to be employed such as nickel or tin plated copper tapes which may significantly alleviate the oxidation of copper. A second way is to extend the thin printed silver contacts further way from the module such that encapsulation once applied is not disturbed. This is carried out currently at our institution (Supporting Information, Figure S-2). Finally, the adhesive remains the most susceptible channel for water and oxygen ingress in the modules and ideally improving the barrier properties of the adhesive would prolong the stability of the modules. This can be done in conjunction with improving edge sealing conditions. An important aspect that emerged during the stability study is the need for abrasion and scratch resistance on the surface of the barrier foil. A small scratch can sprout localized degradation. This can perhaps be alleviated with the use of a second protective film over the encapsulated modules. Finally, this study demonstrates that ITO-free IOne modules have displayed 1 year of outdoor operational and storage stability operating at $95 \%$ of its initial performance and with the improvement in contacting system, the lifetime is expected to improve further with 3-5 years being a reasonable assumption using today's technology.

\section{Experimental Section}

\subsection{Materials and Processing}

IOne is based on a serially-integrated inverted structure in which all layers are processed under fully ambient conditions using roll-to-roll (R2R) printing and coating techniques which are used to process all functional layers at high speed (up to $25 \mathrm{~m} \mathrm{~min}^{-1}$ ). Details on materials and processing can be found elsewhere ${ }^{[1]}$. Briefly, a combination of Ag grid and highly conductive PEDOT:PSS forms the ITO replacement. $\mathrm{ZnO}$, and P3HT:PCBM are slot-die coated consecutively, followed by rotary screen printing of the PEDOT:PSS hole-transport layer, and finally the module stack is completed by screen printing of Ag back electrode. A drying step follows each printing and/or coating step. IOne modules require functionalization which is achieved by the application of a short pulse of high voltage which is also accomplished at customized R2R setup ${ }^{[28]}$. Functional modules were encapsulated in a simple food packaging barrier (Amcor) having a UV filter (cut-off at $390 \mathrm{~nm}$ ) and a barrier performance of $0.01 \mathrm{~cm}^{3} \mathrm{~m}^{-2} \mathrm{bar}^{-1}$ day $^{-1}$ with respect to oxygen (measured according to ASTM D 3985-81) and $0.04 \mathrm{~g} \mathrm{~m}^{-2}$ day $^{-1}$ with respect to water vapor (measured according to ASTM F 372-78). Prior to encapsulation, copper tape $(3 \mathrm{M})$ are placed over the busbars. The modules are sandwiched between the barrier foil with the use of UV curable adhesive DELO ${ }^{\circledR}$ (DELO ${ }^{\mathbb{R}}-$ Katibobond LP 655) applied on the top and bottom surface of the modules. The sandwiched structure is then manually run through the nip pressure of a R2R machine to achieve a homogenous and thin layer of the adhesive. Finally, the encapsulated module is placed under a solar simulator with rich UV content for $5 \mathrm{~min}$, 
which has been found sufficient to cure the adhesive. The cured adhesive has a net thickness of $\sim 10 \mu \mathrm{m}$.

\subsection{The Test Set-Ups}

\subsubsection{India-Denmark Interlaboratory Test}

In India, Gen-I modules were mounted on a makeshift stage on a rooftop at $5^{\circ}$ degree inclination facing south (Bangalore, $13^{\circ} 04^{\prime} \mathrm{N}, 77^{\circ} 36^{\prime} \mathrm{E}$, Elevation $897 \mathrm{~m}$ ). IV characteristics were measured intermittently. Such a test is in accordance with ISOS-O-2 framework. Tests were initiated on 19.06.2012 and ended on 03.10.2013 (404 days; 9696 h). In Denmark, the modules were mounted on a solar tracker and connected to an automated system for continuous recording of IV data every $10 \mathrm{~min}$ directly under outdoor conditions. The modules were intermittently measured under a sulfur plasma lamp equipped solar simulator under 1 sun illumination $\left(1000 \mathrm{~W} \mathrm{~m}^{-2}\right.$; AM $\left.1.5 \mathrm{G}\right)$. The test in Denmark is in accordance with ISOS-O-3 protocol and were conducted in Roskilde $\left(55^{\circ} 41^{\prime} \mathrm{N}, 12^{\circ} 6^{\prime} \mathrm{E}\right.$; elevation $\left.10 \mathrm{~m}\right)$ from 20.06 .2013 to 27.09.2013 (459 days; 11019 h).

\subsubsection{Netherlands-Denmark Interlaboratory Test}

Gen-II modules were tested simultaneously in Netherlands and Denmark starting October 03, 2012 until October 03, 2013 (365 days, 8760 h). In Netherlands, the modules were mounted on a rooftop on a rack facing south (tilt: $30^{\circ} \mathrm{C}$, azimuth: $170^{\circ}$, ventilated, Petten) at ECN $\left(52^{\circ} 47^{\prime} 35^{\prime \prime} \mathrm{N}\right.$, $4^{\circ} 40^{\prime} 49 \mathrm{E}$; Elevation $1 \mathrm{~m}$ ). They were intermittently measured under a calibrated WACOM Class AAA solar simulator proving 1 sun illumination $\left(1000 \mathrm{~W} \mathrm{~m}^{-2}\right.$; AM $1.5 \mathrm{G}, 25^{\circ} \mathrm{C}$ ) according to ISOS-O-1. In Denmark, the modules were placed on a tracker and automatically measured under outdoor illumination as well as intermittently measured indoors according to ISOS-O-3 conditions under as described in the previous section.

Gen-II modules were also evaluated for stability under storage according to ISOS-D-1. The modules were placed in a drawer and intermittently measured under a solar simulator at 1 sun illumination $\left(1000 \mathrm{~W} \mathrm{~m}^{-2}, \mathrm{AM} 1.5 \mathrm{G}, 60^{\circ} \mathrm{C}\right)$. All intermittent measurements made in Denmark were made after an equilibration time of $5 \mathrm{~min}$, followed by measuring three IV curves for each module. The reported values are average of three values.

\subsubsection{Characterization}

Apart from the monitoring of IV characteristics, modules were characterized for quality and post-analysis under an optical micrsocope (Zeiss Axioscope) as well as current imaging using laser beam induced current (LBIC) imaging. More information on the LBIC set-up can be located elsewhere. $^{[39,40]}$

Received: January 4, 2014

Final Version: March 17, 2014

Published online: March 25, 2014
[1] D. Angmo, S. A. Gevorgyan, T. T. Larsen-Olsen, R. R. Søndergaard, M. Hösel, M. Jørgensen, R. Gupta, G. U. Kulkarni, F. C. Krebs, Org. Electron. 2013, 14, 984.

[2] F. C. Krebs, N. Espinosa, M. Hösel, R. R. Søndergaard, M. Jørgensen, Adv. Mater 2014, 26, 29, doi: 10.1002/ adem.201302031.

[3] R. Tipnis, J. Bernkopf, S. Jia, J. Krieg, S. Li, M. Storch, D. Laird, Solar Energy Mater. Solar Cells 2009, 93, 442.

[4] B. Zimmermann, U. Würfel, M. Niggemann, Solar Energy Mater. Solar Cells 2009, 93, 491.

[5] M. T. Lloyd, D. C. Olson, P. Lu, E. Fang, D. L. Moore, M. S. White, M. O. Reese, D. S. Ginley, J. W. P. Hsu, J. Mater. Chem. 2009, 19, 7638.

[6] S. K. Hau, H. Yip, N. S. Baek, J. Zou, K. O’Malley, A. K. Jen, Appl. Phys. Lett. 2008, 92, 253301.

[7] C. H. Peters, I. T. Sachs-Quintana, J. P. Kastrop, S. Beaupré, M. Leclerc, M. D. McGehee, Adv. Energy Mater. 2011, 1, 491.

[8] A. Dupuis, A. Tournebize, P. Bussiere, A. Rivaton, J. Gardette, Eur. Phys. J. Appl. Phys. 2011, 56, 34104.

[9] H. Hintz, C. Sessler, H. Peisert, H. Egelhaaf, T. Chasse, Chem. Mater. 2012, 24, 2739.

[10] G. Williams, Q. Wang, H. Aziz, Adv. Funct. Mater. 2013, 23, 2239.

[11] J. A. Hauch, P. Schilinsky, S. A. Choulis, R. Childers, M. Biele, C. J. Brabec, Solar Energy Mater. Solar Cells 2008, 92, 727.

[12] S. A. Gevorgyan, M. V. Madsen, H. F. Dam, M. Jørgensen, C. J. Fell, K. F. Anderson, B. C. Duck, A. Mescheloff, E. A. Katz, A. Elschner, R. Roesch, H. Hoppe, M. Hermenau, M. Riede, F. C. Krebs, Solar Energy Mater. Solar Cells 2013, 116, 187.

[13] D. E. Motaung, G. F. Malgas, C. J. Arendse, S. E. Mavundla, C. J. Oliphant, D. Knoesen, Solar Energy Mater. Solar Cells 2009, 93, 1674.

[14] H. Hintz, H. Egelhaaf, L. Luer, J. Hauch, H. Peisert, T. Chasse, Chem. Mater. 2011, 23, 145.

[15] M. Manceau, S. Chambon, A. Rivaton, J. Gardette, S. Guillerez, N. Lemaître, Solar Energy Mater. Solar Cells 2010, 94, 1572.

[16] M. Manceau, A. Rivaton, J. Gardette, S. Guillerez, N. Lemaître, Polym. Degrad. Stab. 2009, 94, 898.

[17] M. T. Lloyd, C. H. Peters, A. Garcia, I. V. Kauvar, J. J. Berry, M. O. Reese, M. D. McGehee, D. S. Ginley, D. C. Olson, Solar Energy Mater. Solar Cells 2011, 95, 1382.

[18] M. Schaer, F. Nuesch, D. Berner, W. Leo, L. Zuppiroli, Adv. Funct. Mater. 2001, 11, 116.

[19] S. Gardonio, L. Gregoratti, P. Melpignano, L. Aballe, V. Biondo, R. Zamboni, M. Murgia, S. Caria, A. Kiskinova, Org. Electron. 2007, 8, 37.

[20] C. H. Peters, I. T. Sachs-Quintana, W. R. Mateker, T. Heumueller, J. Rivnay, R. Noriega, Z. M. Beiley, 
E. T. Hoke, A. Salleo, M. D. McGehee, Adv. Mater. 2012, 24, 663.

[21] T. Kugler, M. Logdlund, W. Salaneck, IEEE J. Sel. Top. Quant. Electron. 1998, 4, 14.

[22] Y. L. Gao, Acc. Chem. Res. 1999, 32, 247.

[23] R. J. Davis, J. E. Pemberton, J. Am. Chem. Soc. 2009, 131, 10009.

[24] D. Angmo, I. Gonzalez-Valls, S. Veenstra, W. Verhees, S. Sapkota, S. Schiefer, B. Zimmermann, Y. Galagan, J. Sweelssen, M. Lira-Cantu, R. Andriessen, J. M. Kroon, F. C. Krebs, J. Appl. Polym. Sci. 2013, 130, 944.

[25] M. Jørgensen, K. Norrman, S. A. Gevorgyan, T. Tromholt, B. Andreasen, F. C. Krebs, Adv. Mater. 2012, 24, 580.

[26] N. Grossiord, J. M. Kroon, R. Andriessen, P. W. M. Blom, Org. Electron. 2012, 13, 432.

[27] N. Kim, W. J. Potscavage , Jr. , A. Sundaramoothi, C. Henderson, B. Kippelen, S. Graham, Solar Energy Mater. Solar Cells 2012, 101, 140.

[28] R. Roesch, D. M. Tanenbaum, M. Jørgensen, M. Seeland, M. Baerenklau, M. Hermenau, E. Voroshazi, M. T. Lloyd, Y. Galagan, B. Zimmermann, U. Wuerfel, M. Hoesel, H. F. Dam, S. A. Gevorgyan, S. Kudret, W. Maes, L. Lutsen, D. Vanderzande, R. Andriessen, G. TeranEscobar, M. Lira-Cantu, A. Rivaton, G. Y. Uzunoglu, D. Germack, B. Andreasen, M. V. Madsen, K. Norrman, H. Hoppe, F. C. Krebs, Energy Environ. Sci. 2012, 5, 6521.

[29] S. Cros, R. de Bettignies, S. Berson, S. Bailly, P. Maisse, N. Lemaitre, S. Guillerez, Solar Energy Mater. Solar Cells 2011, 95(Suppl. 1), S65.

[30] D. M. Tanenbaum, H. F. Dam, R. Roesch, M. Jørgensen, H. Hoppe, F. C. Krebs, Solar Energy Mater. Solar Cells 2012, 97, 157.
[31] M. O. Reese, S. A. Gevorgyan, M. Jørgensen, E. Bundgaard, S. R. Kurtz, D. S. Ginley, D. C. Olson, M. T. Lloyd, P. Moryillo, E. A. Katz, A. Elschner, O. Haillant, T. R. Currier, V. Shrotriya, M. Hermenau, M. Riede, K. R. Kirov, G. Trimmel, T. Rath, O. Ingañas, F. Zhang, M. Andersson, K. Tvingstedt, M. Lira-Cantu, D. Laird, C. McGuiness, S. Gowrisanker, M. Pannone, M. Xiao, J. Hauch, R. Steim, D. M. DeLongchamp, R. Roesch, H. Hoppe, N. Espinosa, A. Urbina, G. YamanUzunoglu, J. Bonekamp, A. J. J. M. van Breemen, C. Girotto, E. Voroshazi, F. C. Krebs, Solar Energy Mater. Solar Cells 2011, 95, 1253.

[32] R. Roesch, K. Eberhardt, S. Engmann, G. Gobsch, H. Hoppe, Solar Energy Mater. Solar Cells 2013, 117, 59.

[33] K. Kawano, R. Pacios, D. Poplavskyy, J. Nelson, D. D. C. Bradley, J. R. Durrant, Solar Energy Mater. Solar Cells 2006, 90, 3520.

[34] A. M. Nardes, M. Kemerink, M. M. de Kok, E. Vinken, K. Maturova, R. A. J. Janssen, Org. Electron. 2008, 9, 727.

[35] K. Norrman, M. V. Madsen, S. A. Gevorgyan, F. C. Krebs, J. Am. Chem. Soc. 2010, 132, 16883.

[36] S. R. Dupont, M. Oliver, F. C. Krebs, R. H. Dauskardt, Solar Energy Mater. Solar Cells 2012, 97, 171.

[37] E. A. Katz, D. Faiman, S. M. Tuladhar, J. M. Kroon, M. M. Wienk, T. Fromherz, F. Padinger, C. J. Brabec, N. S. Sariciftci, J. Appl. Phys. 2001, 90, 5343.

[38] M. Hösel, R. R. Søndergaard, M. Jørgensen, F. C. Krebs, Adv. Eng. Mater. 2013, 15, 1068.

[39] D. Angmo, S. A. Gevorgyan, T. T. Larsen-Olsen, R. Søndergaard, M. Hösel, M. Jørgensen, R. Gupta, G. U. Kulkarni, F. C. Krebs, Org. Electron. 2013, 14, 984.

[40] F. C. Krebs, R. Søndergaard, M. Jørgensen, Solar Energy Mater. Solar Cells 2011, 95, 1348. 